\title{
Article \\ Characteristics of Flow over Rectangular Labyrinth Weirs with Round Corners
}

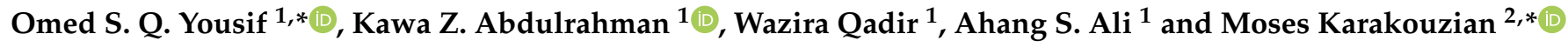 \\ 1 Department of Water Resources Engineering, College of Engineering, University of Sulaimani, \\ Sulaymaniyah 46002, Kurdistan Region, Iraq; kawa.abed@univsul.edu.iq (K.Z.A.); \\ wazera.qadir@univsul.edu.iq (W.Q.); ahang.ali@univsul.edu.iq (A.S.A) \\ 2 Civil and Environmental Engineering and Construction, University of Nevada, 4505 Maryland Parkway, \\ Las Vegas, NV 89154, USA \\ * Correspondence: omed.qadir@univsul.edu.iq (O.S.Q.Y.); mkar@unlv.nevada.edu (M.K.); \\ Tel.: +702-682-7096 (M.K.)
}

check for updates

Citation: Yousif, O.S.Q.;

Abdulrahman, K.Z.; Qadir, W.; Ali, A.S.; Karakouzian, M. Characteristics of Flow over Rectangular Labyrinth Weirs with Round Corners. Hydrology 2021, 8, 158. https://doi.org/ $10.3390 /$ hydrology 8040158

Academic Editor: Monzur A. Imteaz

Received: 30 August 2021

Accepted: 13 October 2021

Published: 18 October 2021

Publisher's Note: MDPI stays neutral with regard to jurisdictional claims in published maps and institutional affiliations.

Copyright: (c) 2021 by the authors. Licensee MDPI, Basel, Switzerland. This article is an open access article distributed under the terms and conditions of the Creative Commons Attribution (CC BY) license (https:/ / creativecommons.org/licenses/by/ $4.0 /)$.

\begin{abstract}
The hydraulic performance of round-cornered rectangular labyrinth weirs with varying weir heights and effective lengths has not been explored in the existing literature to the authors' knowledge. The purpose of this experimental study was to see how the height and effective length of round-cornered rectangular labyrinth weirs affect their discharge efficiency. Nine flat-crested rectangular labyrinth weirs made of high-density polyethylene (HDPE) were tested in a rectangular flume under various discharges to fulfill the goals of this study. The discharge coefficients for the weirs were then calculated. The hydraulic efficiency of weirs with round corners increases as the weir height $(P)$ increases, according to the findings; however, with effective length of the weir to channel width ratios $\left(L_{C} / B\right) \leq 1.78$, the effect of the weir height diminishes. For the $H_{T} / P$ ranges used in this study, $0.1 \leq H_{T} / P \leq 0.65$, the round-cornered rectangular labyrinth weirs with higher $L_{C} / B$ ratios (greater $M$ values) showed improved hydraulic efficiency. Furthermore, the effects of the roundcornered rectangular labyrinth weirs' headwater inflation can be mitigated by increasing the effective length of the weirs; by increasing $M$ values $\left(L_{C} / B\right.$ ratios). Using multiple linear regression analysis, a satisfactory correlation equation was found between discharge coefficients of round-cornered rectangular labyrinth weirs, $C_{B}$, and the other parameters, $L_{C}, P$, and $h$.
\end{abstract}

Keywords: rectangular labyrinth weirs; spillways; discharge coefficient; corner shape; weir's hydraulic performance

\section{Introduction}

Constructing a labyrinth weir is a practical and cost-effective approach to improving a dam's spillway discharge capacity without expanding the existing spillway channel width or water heads over the crest [1-3]. A labyrinth weir is a weir with a crest length that is greater than the width of a channel or spillway [4]. It is usually made by placing linear weirs in a zigzag pattern and folding them in plan view. Because labyrinth weirs are usually made up of repeated simple shapes (cycles) in plan-view, such as half-circular, circular, triangular, rectangular, and trapezoid (trapezoidal) shapes, both their design and construction are very cost-effective [5-7]. The discharge, head of water flowing over the weirs, and weir geometry are the elements that influence their performance $[4,8]$. The total crest length of the weir (effective crest length, $L_{C}$ ), cycle width, sidewall angle, upstream wall height, downstream wall height, wall thickness $(t)$, crest shape, and weir apex shape horizontally normal to the flow direction (apex configuration or weir tip shape) are the factors that control the weir geometry $[1,3,6]$.

The rectangular labyrinth weir $[5,9,10]$ is one of the labyrinth weir forms. A rectangular labyrinth weir is a labyrinth weir with two adjacent weir sides that form a right angle (90 degrees); the weir tips (apexes) are perpendicular to the sidewalls [4]. This form 
has many advantages, such as a structurally strong body and being economically costeffective [11,12], although these weirs have their drawbacks as well. One of the main drawbacks, similar to triangular and trapezoidal labyrinth weirs, is nappe interference (nappe collision) problems. When the water sheets running over two neighboring walls meet, this is known as nappe interference. As a result, the discharge efficiency of the labyrinth weirs is reduced [2]. The nappe interference can form in the upstream corners of rectangular weirs due to the collision of flow sheets from the upstream apex and sidewalls. As a result, the discharge efficiency of the rectangular labyrinth weirs may be reduced. It is thought that upgrading the corner designs of rectangular labyrinth weirs will reduce or eliminate nappe interference and boost hydraulic efficiency. Although many researchers have looked at the hydraulic performance of rectangular labyrinth weirs $[4,5,9,10,12-14]$, the hydraulic performance of rectangular labyrinth weirs with different corner shapes has not been explored in the existing literature, except by Yousif and Karakouzian (2020) [15].

Yousif and Karakouzian (2020), in an attempt to improve the hydraulic performance of rectangular labyrinth weirs, so as to alleviate the adverse effects of nappe interference and headwater inflation, studied the effects of the corner shape on the flow properties over the labyrinth weirs. In their study, the effects of different corner shapes on the hydraulic performance of the rectangular labyrinth weirs were evaluated. It was found that by modifying the corner shape from a sharp (90 degree) to a round shape, the discharge capacity was increased by $15 \%$ on average; however, the effects of the height and effective length of the rectangular labyrinth weirs with round corners on the hydraulic efficiency were not addressed, which are the main aims of this study.

\section{Materials and Methods}

Nine rectangular labyrinth weirs were constructed and placed in a laboratory flume (S6MKII Teaching and Research Flume, built by Armfield company) at the University of Sulaimani to meet the goals of this study. High-density polyethylene (HDPE) was used to make the models (1-cm-thick walls). Round corners and flat crest shapes characterized the rectangular labyrinth weir versions. Three different weir heights were tested, as well as three different effective lengths. The slope of the flume's steel bed $(5 \mathrm{~m} \mathrm{long}, 0.3 \mathrm{~m}$ wide, $0.45 \mathrm{~m}$ deep, with Plexiglas sidewalls) was adjusted to zero for all runs. A sketch of the models and a photograph of the flume are shown in Figures 1 and 2, respectively. The details of the models examined in this study are shown in Table 1.

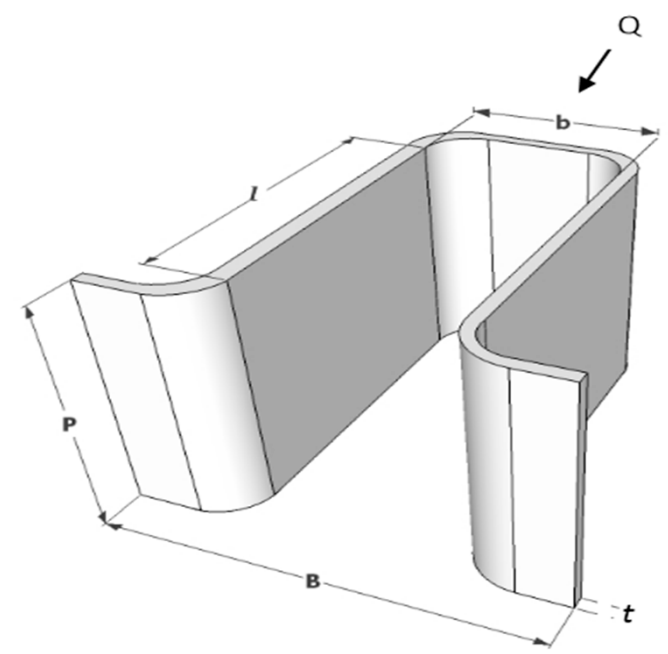

Figure 1. Isometric view of round-cornered rectangular labyrinth weir and definition of the main symbols. 


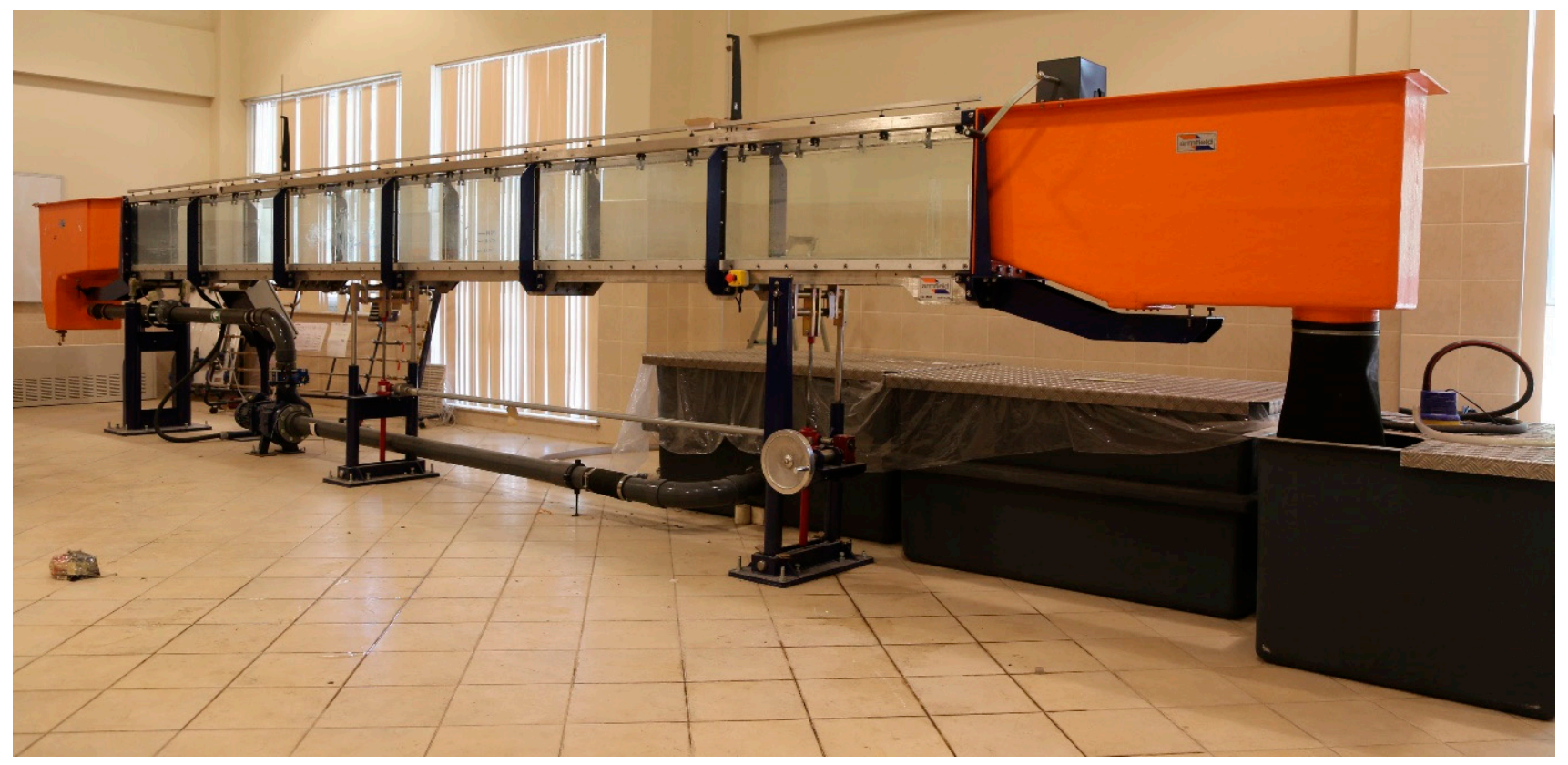

Figure 2. Armfield S6-MKII laboratory flow channel.

The models were then evaluated under different steady-state settings without artificial aeration devices after being placed in the middle of the flume in a reversed orientation. An ultrasonic flowmeter was used to measure the steady discharges, which ranged from 0.003 to $0.03 \mathrm{~m}^{3} / \mathrm{s}$. A point gauge with $0.1 \mathrm{~mm}$ accuracy was employed to measure the depth of water flowing over the crest of the models, h (see Figure 3), at a distance greater than or equal to $5 \mathrm{~h}$ upstream of the weirs. After fifteen to twenty minutes had passed and the steady-state situation had stabilized, measurements were taken for each discharge. In each run, which lasted 3 to $4 h$, photographs, videos, and visual inspections were used to document the hydraulic performance of the models. The details of the experiments are presented in Table 2.
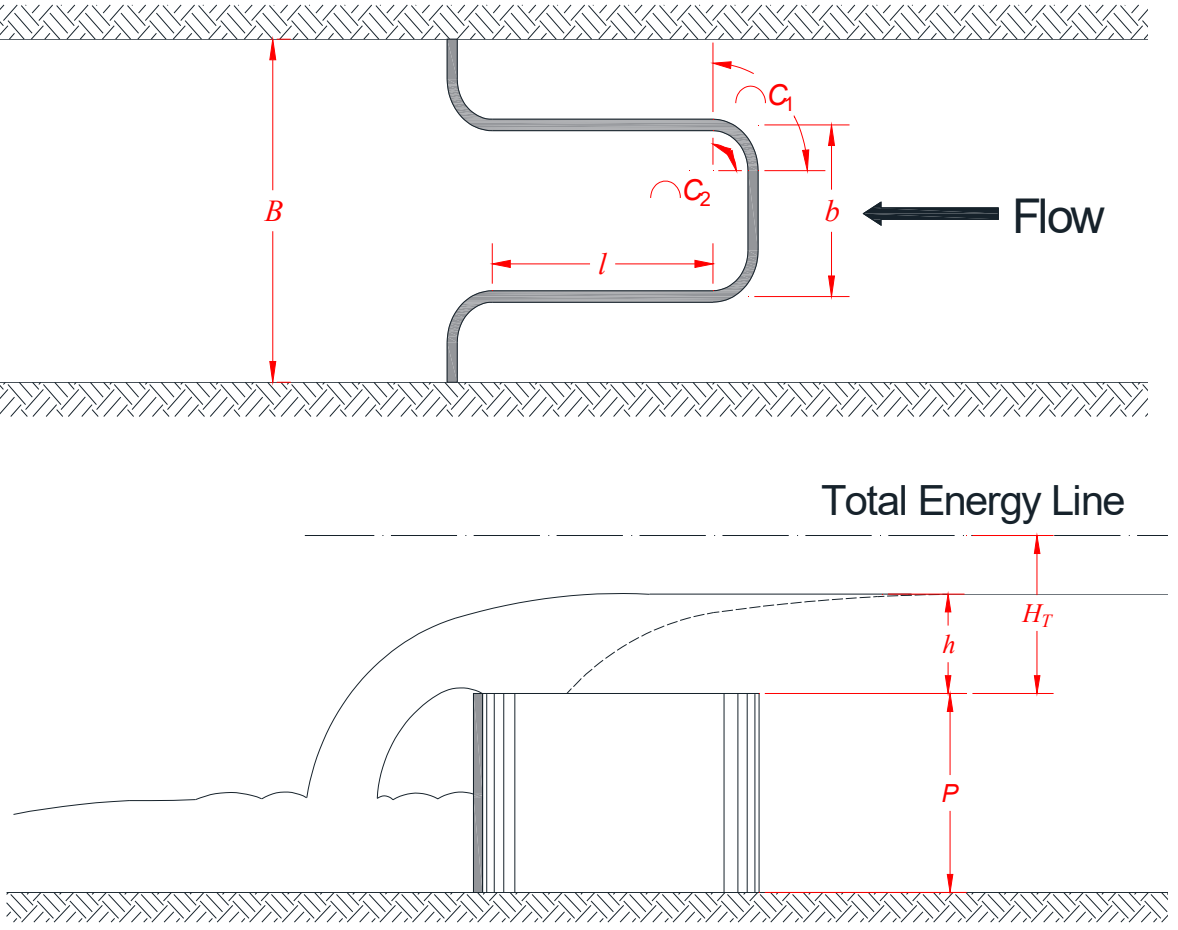

Figure 3. Illustrative chart of the flow over the rectangular labyrinth weirs. 
Table 1. Characteristics of the weir models.

\begin{tabular}{ccccccccccc}
\hline Model & $\boldsymbol{B}(\mathbf{m m})$ & $\boldsymbol{b}(\mathbf{m m})$ & $\boldsymbol{l}(\mathbf{m m})$ & $\boldsymbol{t}(\mathbf{m m})$ & $\boldsymbol{C}_{\boldsymbol{1}}(\mathbf{m m})$ & $\boldsymbol{C}_{\mathbf{2}}(\mathbf{m m})$ & $\boldsymbol{P}(\mathbf{m m})$ & $\boldsymbol{L}_{\boldsymbol{C}} \boldsymbol{~}^{(\mathbf{m m})}$ & $\boldsymbol{L}_{\boldsymbol{C}} / \boldsymbol{B}$ & $\boldsymbol{B} / \boldsymbol{P}$ \\
\hline M1 & 300 & 150 & 75 & 10 & 42.5 & 32.5 & 150 & 533.6 & 1.78 \\
M2 & 300 & 150 & 75 & 10 & 42.5 & 32.5 & 200 & 533.6 & 1.78 \\
M3 & 300 & 150 & 75 & 10 & 42.5 & 32.5 & 250 & 533.6 & 1.78 \\
M4 & 300 & 150 & 225 & 10 & 42.5 & 32.5 & 200 & 836 & 2.79 \\
M5 & 300 & 150 & 225 & 10 & 42.5 & 32.5 & 200 & 836 & 2.79 \\
M6 & 300 & 150 & 225 & 10 & 42.5 & 32.5 & 200 & 836 & 2.79 \\
M7 & 300 & 150 & 375 & 10 & 42.5 & 32.5 & 250 & 1136 & 3.79 \\
M8 & 300 & 150 & 375 & 10 & 42.5 & 32.5 & 250 & 1136 & 3.79 & 1.5 \\
M9 & 300 & 150 & 375 & 10 & 42.5 & 32.5 & 250 & 1136 & 3.79 \\
\hline
\end{tabular}

* The effective length (centerline length) of the weir.

Table 2. Details of the experimental runs.

\begin{tabular}{cccc}
\hline Model & $\boldsymbol{Q}, \mathbf{m}^{\mathbf{3}} / \mathbf{s}$ & $\boldsymbol{h}, \mathbf{m}$ & $\left(\boldsymbol{H}_{T} / \boldsymbol{P}\right)^{*}$ \\
\hline M1 & $0.00295-0.0246$ & $0.02-0.09$ & $0.1345-0.639$ \\
M2 & $0.00296-0.0239$ & $0.02-0.09$ & $0.1005-0.4693$ \\
M3 & $0.00285-0.0199$ & $0.02-0.08$ & $0.0803-0.3283$ \\
M4 & $0.00368-0.0285$ & $0.02-0.08$ & $0.1351-0.5913$ \\
M5 & $0.00412-0.0305$ & $0.02-0.08$ & $0.101-0.4338$ \\
M6 & $0.00412-0.0294$ & $0.02-0.08$ & $0.805-0.338$ \\
M7 & $0.00475-0.0287$ & $0.02-0.07$ & $0.1363-0.5313$ \\
M8 & $0.00421-0.0305$ & $0.02-0.07$ & $0.101-0.3863$ \\
M9 & $0.00429-0.0307$ & $0.02-0.07$ & $0.0806-0.3009$ \\
\hline
\end{tabular}

${ }^{*} P=$ weir height; $H_{T}=$ total head over the weir measured at a distance $\geq 5 h$, see Figure 3 .

\section{Results and Discussion}

In this experimental study, the hydraulic performance of nine round-cornered rectangular labyrinth weirs was evaluated. To determine the coefficient of discharge for the weirs, the head-discharge correlations shown below were used $[8,11]$ :

$$
Q=\frac{2}{3} \cdot \sqrt{2 g} \cdot C_{L} \cdot L_{C} \cdot H_{T}^{1.5}=\frac{2}{3} \cdot \sqrt{2 g} * C_{B} \cdot B \cdot\left(h+\frac{V_{a}^{2}}{2 g}\right)^{1.5}
$$

where $Q$ is the overflow discharge, $g$ is the gravitational acceleration, $C_{L}$ and $C_{B}$ are the coefficients of discharge (dimensionless), $L_{C}$ is the centerline length (or the effective length) of the weir crest, $B$ is the width of the channel (flume), $H_{T}$ is the total head of the water flowing over the weirs (see Figure 3 ) $h$ is the depth of water flowing over the weir crest, and $V_{a}$ is the velocity of approach $\{Q /[B *(h+P)]\}$. Figure 4 shows the photographs of all models tested for the same water depth, $h=70 \mathrm{~mm}$.

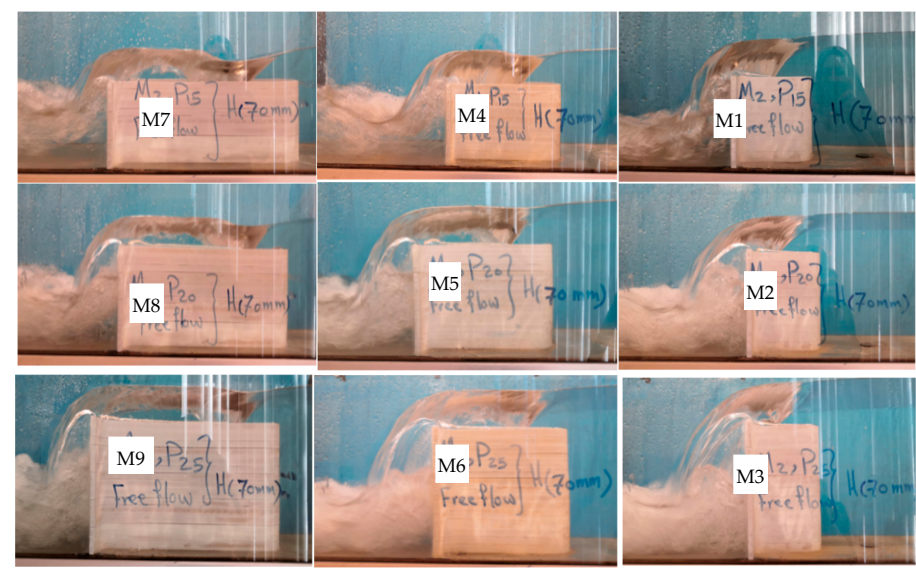

Figure 4. Photographs of the models, $h=70 \mathrm{~mm}$. 
To identify and quantify the effects of the variables studied here, the experimental results are presented in both figures and tables, as shown in Figures 5-22 and Tables 3-5.

\subsection{Hydraulic Performance of the Models}

Figures $5-13$ show the values of the discharge coefficient $\left(C_{L}\right)$ for each model plotted against $H_{T} / P$ ratios to evaluate the hydraulic performance of the labyrinth weirs. The changes in $C_{L}$ values for $H_{T} / P$ ratios can be divided into two parts based on the figures for the range of $H_{T} / P$ from 0.08 to 0.65 . The value of $C_{L}$ increases for modest discharges up to $H_{T} / P \leq 0.1$ to 0.22 (depending on the weir height and effective length), whereas it decreases after those values. The depth of flow over labyrinth weirs at which self-aeration ceases is the water depth at which the $C_{L}$ value begins to decline [5]. Headwater inflation, nappe interaction and interferences, or both, are responsible for the decrease in $C_{L}$ values [2,5]. The values of $C_{L}$ and the $H_{T} / P$ ratios are correlated using the 4 th degree polynomial model, as illustrated below:

$$
C_{L}=a_{0}+a_{1}\left(\frac{H_{T}}{P}\right)+a_{2}\left(\frac{H_{T}}{P}\right)^{2}+a_{3}\left(\frac{H_{T}}{P}\right)^{3}+a_{4}\left(\frac{H_{T}}{P}\right)^{4}
$$

Table 3 presents the values of the coefficient of the polynomial model, $a_{0}$ to $a_{5}$, as well as $R^{2}$.

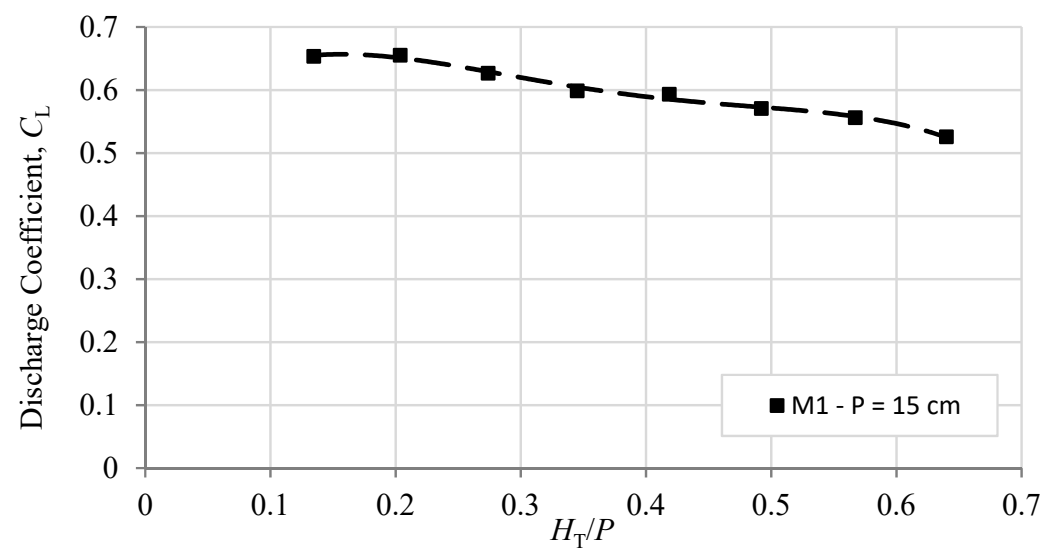

Figure 5. Variations in the discharge coefficient, $C_{L}$, as a function of the $H_{T} / P$ ratio for the M1 model.

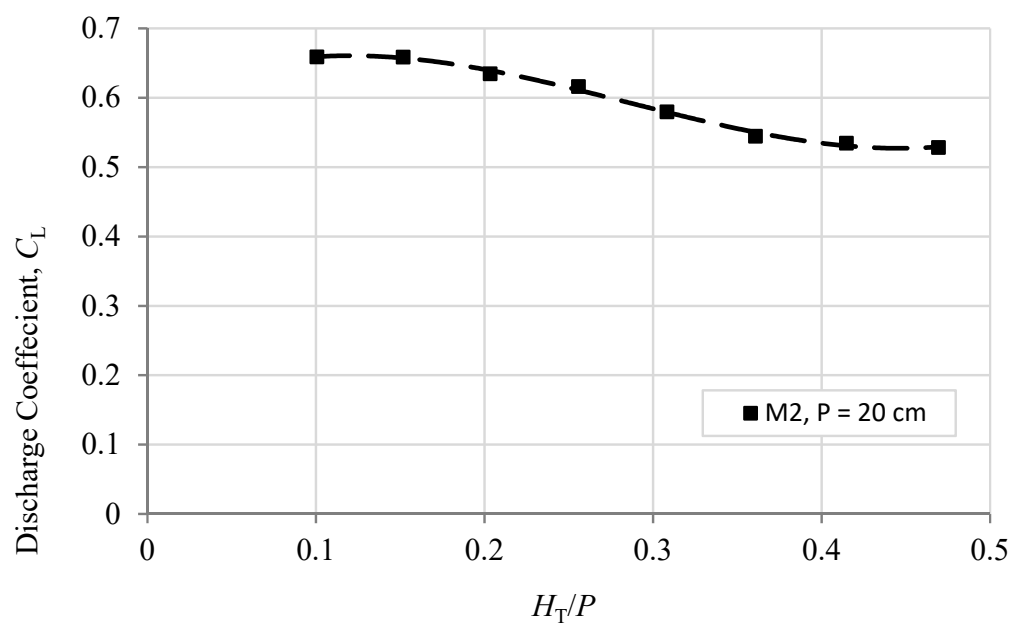

Figure 6. Variations in the discharge coefficient, $C_{L}$, as a function of the $H_{T} / P$ ratio for the M2 model. 


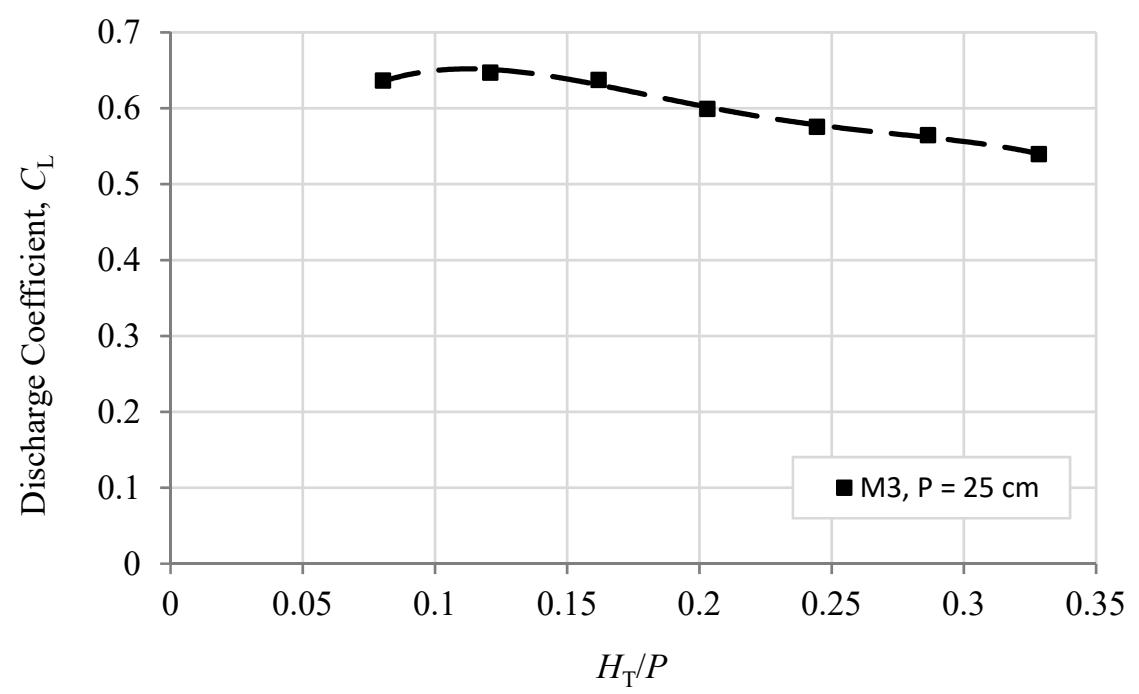

Figure 7. Variations in the discharge coefficient, $C_{L}$, as a function of the $H_{T} / P$ ratio for the M3 model.

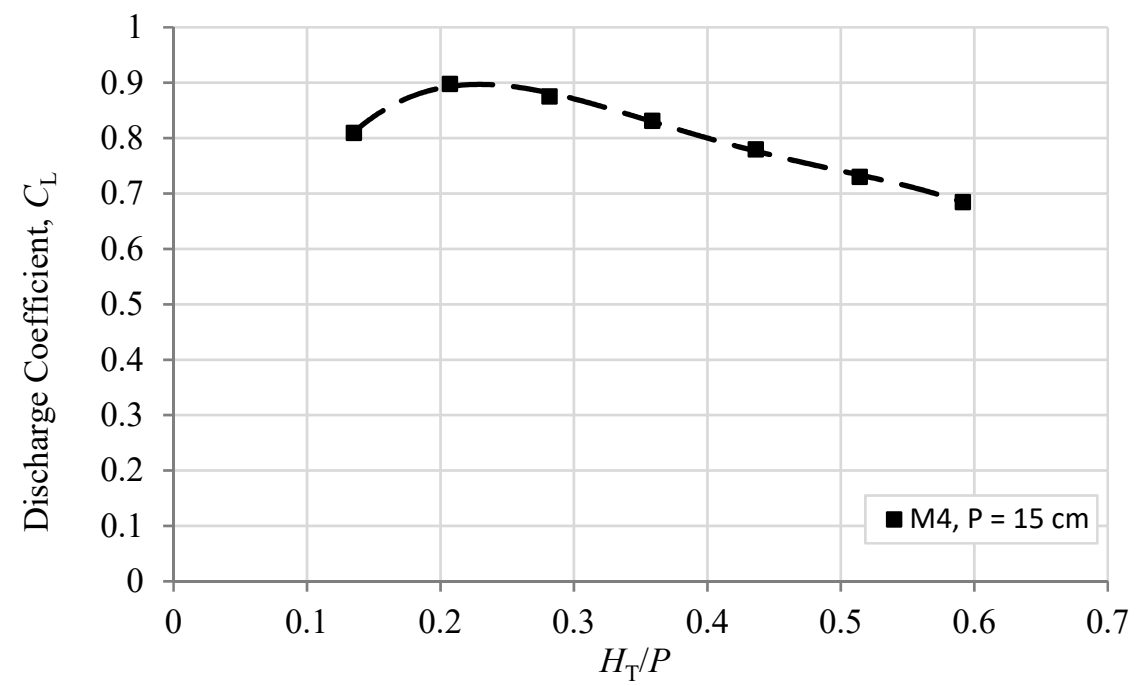

Figure 8. Variations in the discharge coefficient, $C_{L}$, as a function of the $H_{T} / P$ ratio for the M4 model.

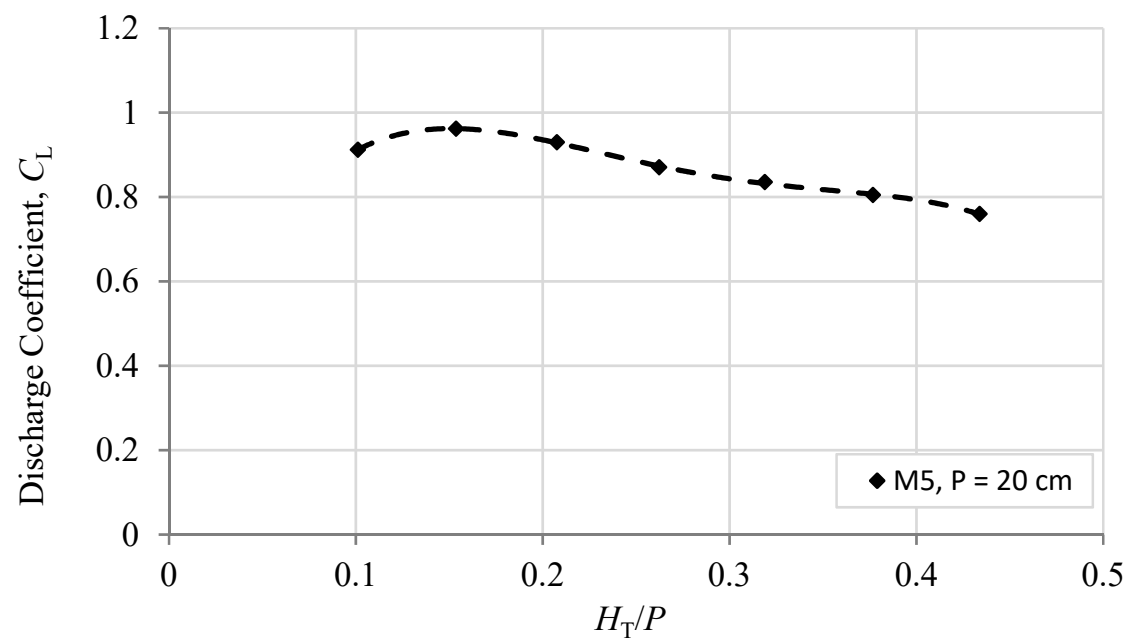

Figure 9. Variations in the discharge coefficient, $C_{L}$, as a function of the $H_{T} / P$ ratio for the M5 model. 


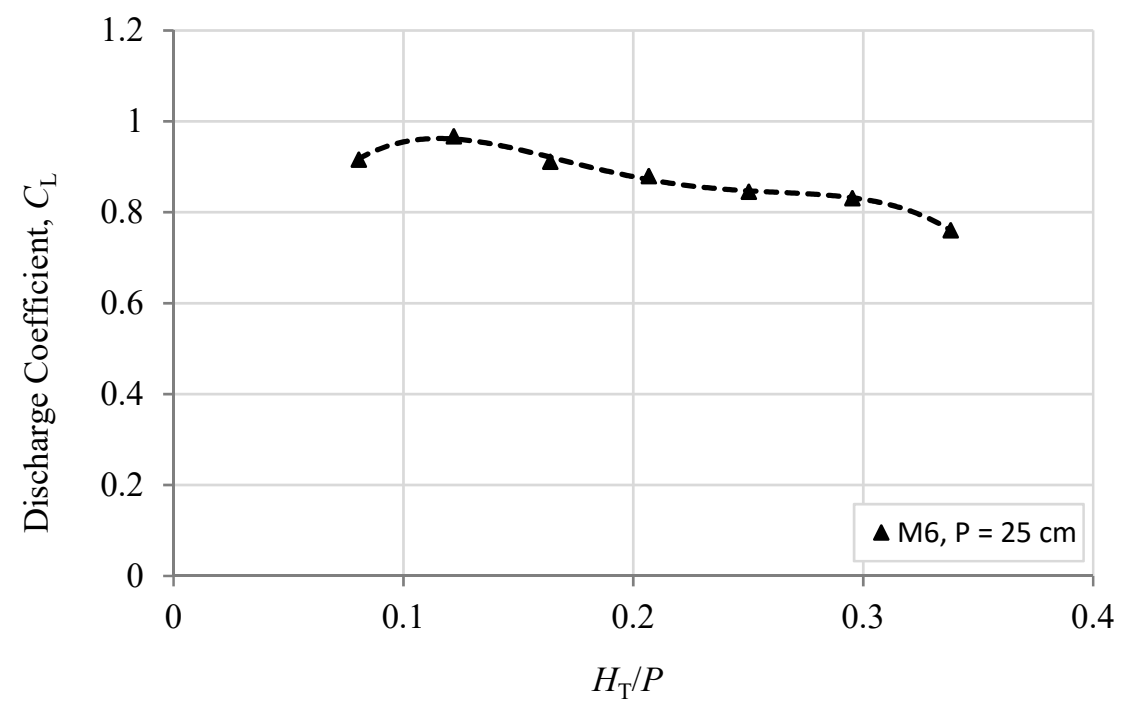

Figure 10. Variations in the discharge coefficient, $C_{L}$, as a function of the $H_{T} / P$ ratio for the M6 model.

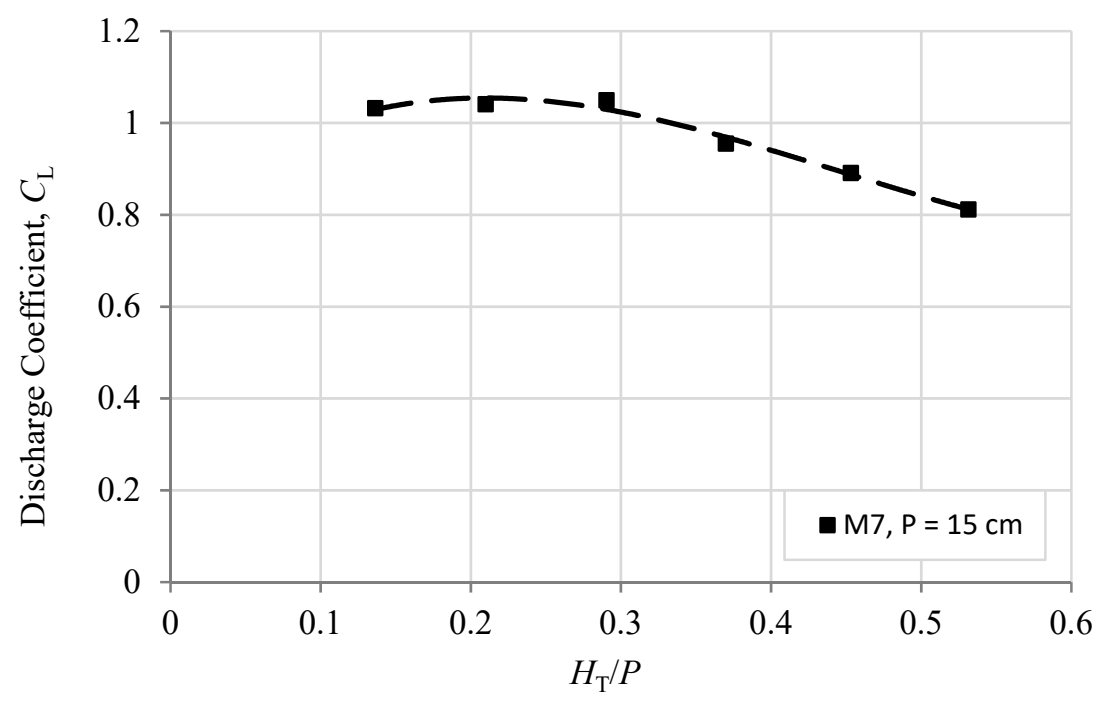

Figure 11. Variations in the discharge coefficient, $C_{L}$, as a function of the $H_{T} / P$ ratio for the M7 model.

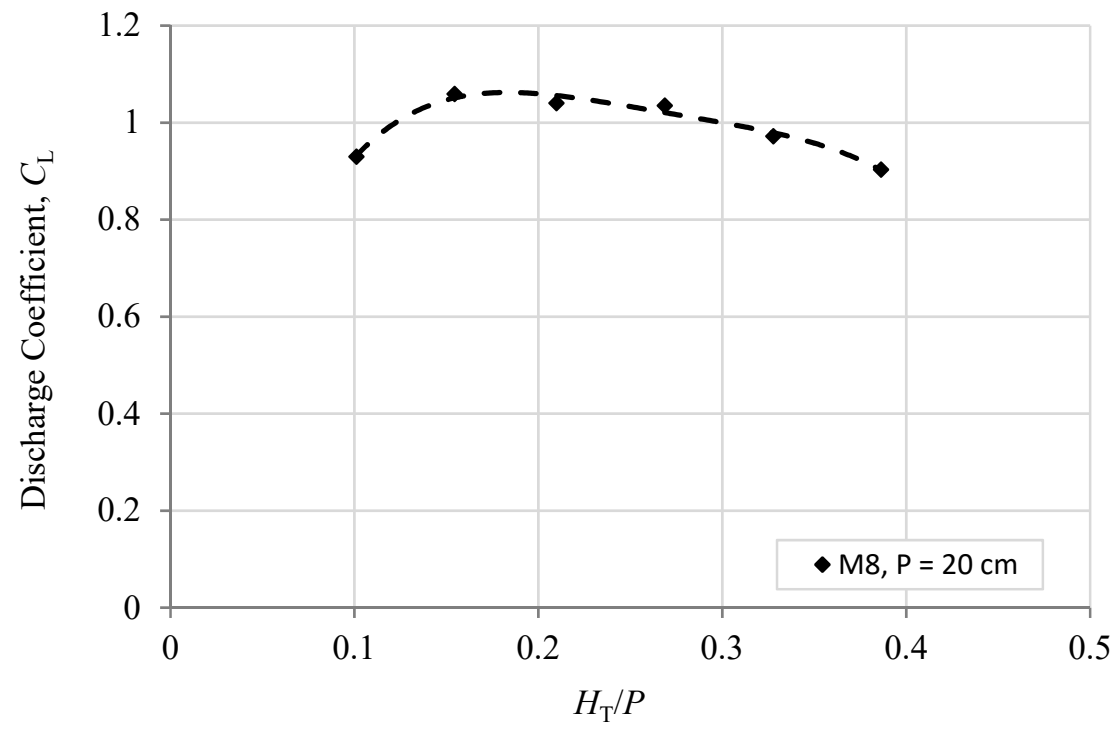

Figure 12. Variations in the discharge coefficient, $C_{L}$, as a function of the $H_{T} / P$ ratio for the M8 model. 


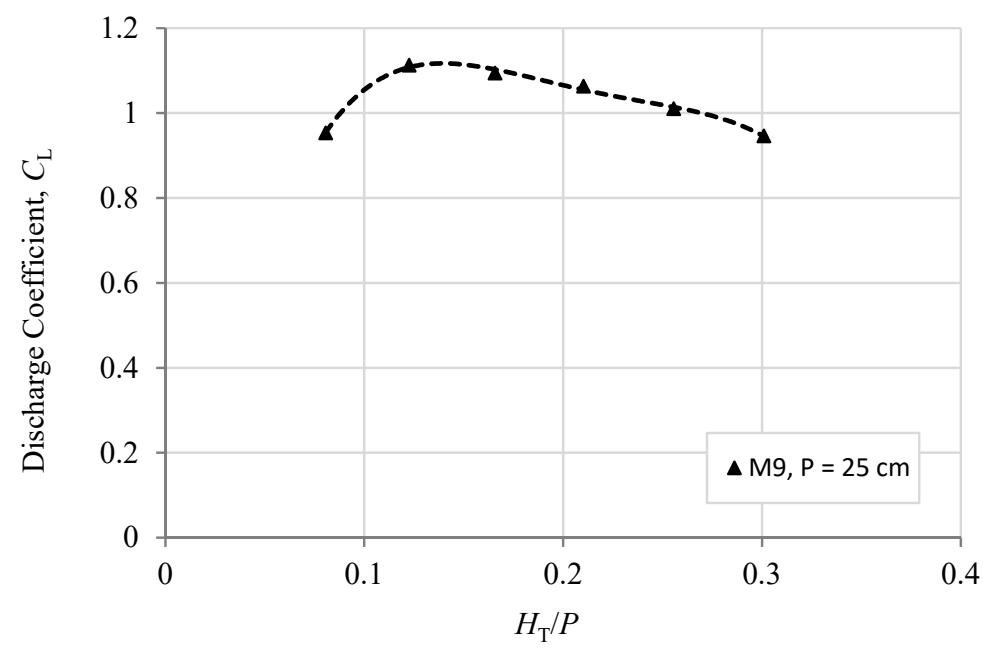

Figure 13. Variations in the discharge coefficient, $C_{L}$, as a function of the $H_{T} / P$ ratio for the M9 model.

Table 3. Coefficients and $R^{2}$ values of the polynomial models.

\begin{tabular}{ccccccc}
\hline Model & $\boldsymbol{a}_{\mathbf{0}}$ & $\boldsymbol{a}_{\mathbf{1}}$ & $\boldsymbol{a}_{\mathbf{2}}$ & $\boldsymbol{a}_{\mathbf{3}}$ & $\boldsymbol{a}_{\mathbf{4}}$ & $\boldsymbol{R}^{\mathbf{2}}$ \\
\hline M1 & 0.5257 & 2.0505 & -10.48 & 19.409 & -12.566 & 0.991 \\
M2 & 0.5953 & 1.1898 & -6.202 & 6.8072 & 0.7842 & 0.9954 \\
M3 & 0.3328 & 7.3478 & -57.45 & 176 & -192.84 & 0.992 \\
M4 & 0.1188 & 9.0016 & -35.874 & 57.483 & -33.527 & 0.9975 \\
M5 & 0.2301 & 12.801 & -76.787 & 183.44 & -156.7 & 0.9992 \\
M6 & 0.1195 & 19.614 & -158.05 & 513.9 & -595.85 & 0.9926 \\
M7 & 0.9729 & 0.119 & 4.778 & -21.419 & 20.596 & 0.9839 \\
M8 & -0.0711 & 17.962 & -102.55 & 251.25 & -231.1 & 0.9728 \\
M9 & -0.5141 & 33.727 & -249.88 & 786.4 & 913.58 & 0.9924 \\
\hline
\end{tabular}

\subsection{Effects of Weir Height on the Hydraulic Efficiency}

With increasing weir height $(P)$, the hydraulic efficiency of rectangular labyrinth weirs with round corners improves; however, as demonstrated in Figure 14, the influence of weir height decreases for weirs with effective length of the weir crest to channel width ratios $\left(L_{C} / B\right) \leq 1.78$. In other words, for weirs with $L_{C} / B=1.78$ (M1, M2, and M3), the change in weir height, $P$, had no effect; comparable variations in $C_{B}$ values were seen for the three different weir heights, $P=15,20$, and $25 \mathrm{~cm}$, respectively. As a result, the hydraulic efficiency of rectangular labyrinth weirs with $L_{C} / B$ ratios less than or equal to 1.78 is unaffected by weir height. As shown in Figures 15 and 16 and Table 4, the values of $C_{B}$ for labyrinth weirs with $L_{C} / B$ ratios $\geq 2.79$ were greater than those with lower heights; the $C_{B}$ values for weirs with $P \geq 200 \mathrm{~mm}$ were higher than those with $P=150 \mathrm{~mm}\left(L_{C} / B\right.$ ratios $=1.78$ ). This is because longer rectangular labyrinth weirs have less headwater inflation and nappe interaction; for rectangular labyrinth weirs with $L_{C} / B$ ratios $\geq 2.79$ and $B / P$ ratios $\leq 1.5$, the effects of nappe interaction and interferences are reduced due to the deeper downstream throat of the weirs, which leads to an increase in the weirs discharge capacity.

As the $B / P$ ratio was reduced from 2 to 1.5 , the $C_{B}$ values of the M5 and M6 models (relative to M4) increased by $9 \%$ on average, as shown in Figure 15 and Table 4 . A similar pattern was seen for models M7, M8, and M9, as illustrated in Figure 16 and Table 4. The $C_{B}$ values of the M8 model (relative to M7) improved by 4.3 percent on average as the $B / P$ ratio decreased from 2 to 1.5 . The $C_{B}$ values of the M9 model (relative to the M7) increased by 8.3 percent on average as the $B / P$ ratio declined from 2 to 1.2 . 


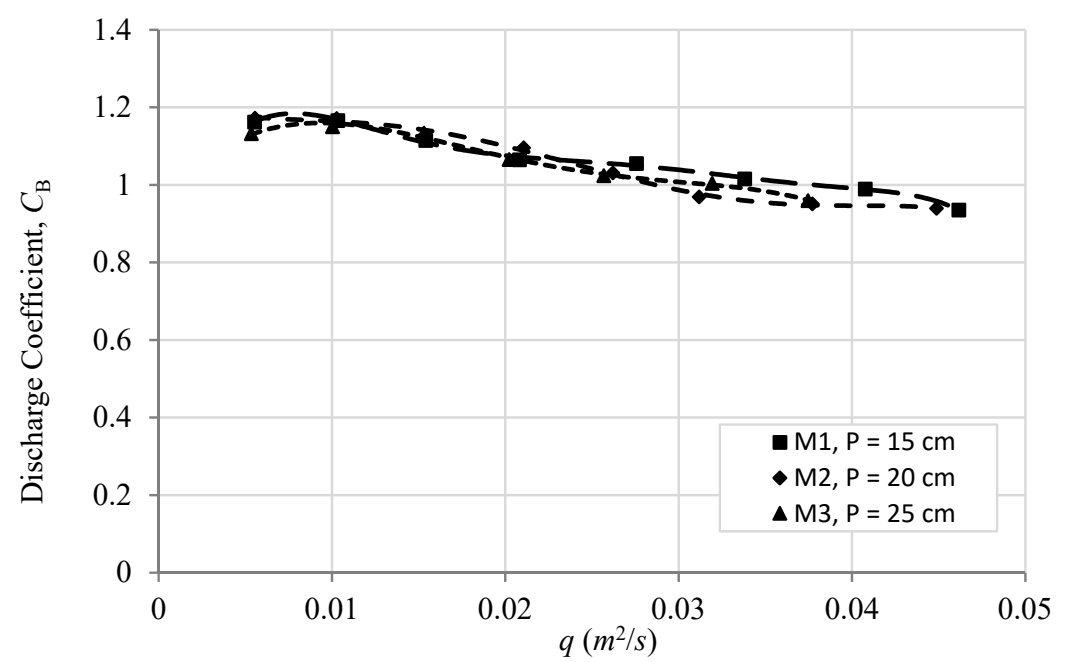

Figure 14. Discharge coefficient, $C_{B}$, vs. unit discharge, $q$, for models M1, M2, and M3.

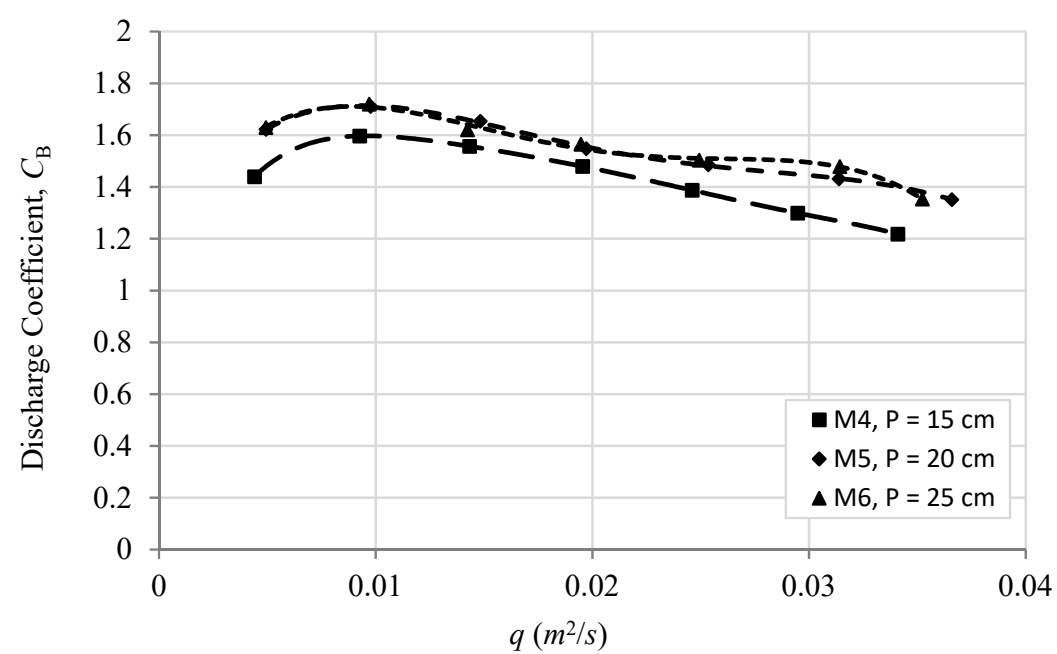

Figure 15. Discharge coefficient, $C_{B}$, vs. unit discharge, $q$, for models M4, M5, and M6.

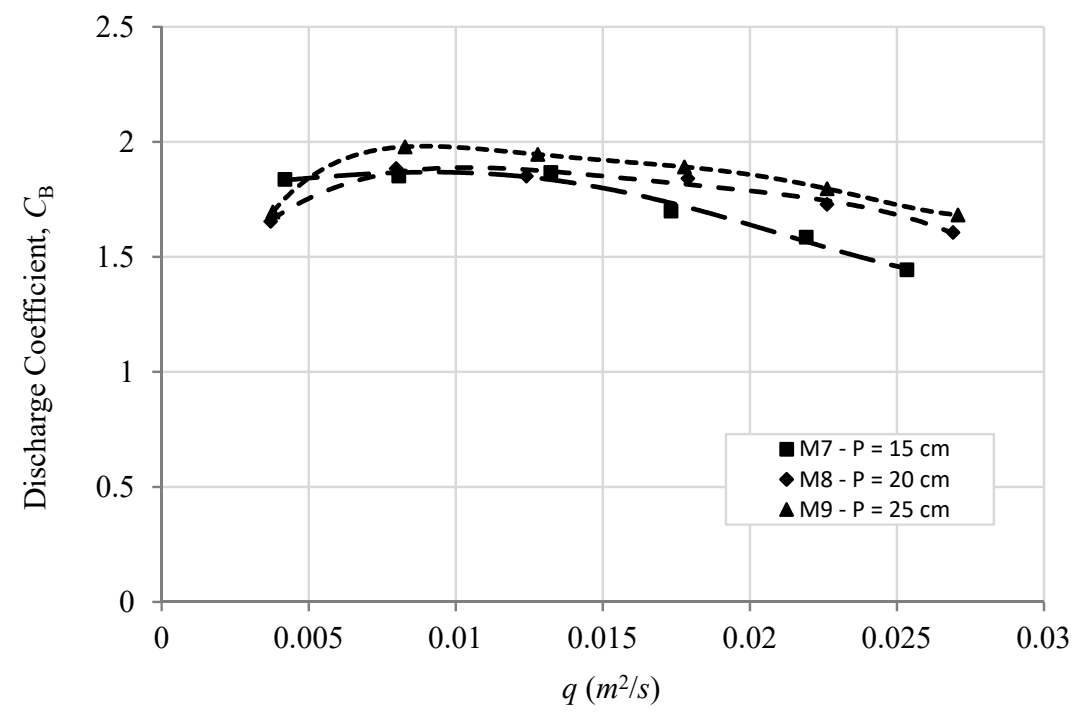

Figure 16. Discharge coefficient, $C_{B}$, vs. unit discharge, $q$, for models M7, M8, and M9. 
Table 4. Changes in the $C_{B}$ values due to the weir height.

\begin{tabular}{ccccc}
\hline \multirow{2}{*}{ Parameters } & \multicolumn{4}{c}{ Percentage Changes } \\
\cline { 2 - 5 } & M5/M4 & M6/M4 & M8/M7 & M9/M7 \\
\hline $\begin{array}{c}\text { Weir Length to Channel Width } \\
\text { ratios, } L_{C} / B\end{array}$ & 2.79 & 2.79 & 3.79 & 3.79 \\
Coefficient of Discharge $\left(C_{B}\right)$ & $\begin{array}{c}5.3-12 \\
(8.8) *\end{array}$ & $\begin{array}{c}4.45-13.5 \\
(9.4) *\end{array}$ & $\begin{array}{c}0.0-13.6 \\
(4.3) *\end{array}$ & $\begin{array}{c}\text { * } \\
\text { (8.0-18 }\end{array}$ \\
\hline
\end{tabular}

*Average values.

\subsection{Effects of Weir Length on the Hydraulic Efficiency}

The rectangular labyrinth weirs with greater $L_{C} / B$ ratios (higher $M$ values) showed higher hydraulic efficiency for the discharge rates utilized in this study, $0.003 \leq Q \leq 0.03 \mathrm{~m}^{3} / \mathrm{s}$. Figures 17-19 show that weirs with greater $L_{C} / B$ ratios (higher $M$ values) gave higher total discharges, $Q$, with the same $H_{T} / P$ ratios. Table 5 shows that when the effective length of the weirs increased by $57 \%$, the total discharge, $Q$, increased by $33 \%$ to $54 \%$. When the effective length increased by 113 percent, the percentages grew to almost $80 \%$. This was mainly because as the $M$ value ( $L_{C} / B$ ratio) increases, the discharge capacity also increases.

The coefficients of discharge, $C_{L}$, of the labyrinth weirs with greater $M$ values were higher than those of the labyrinth weirs with smaller $M$ values (Figures 20-22). In other words, the $C_{L}$ values for weirs with $L_{C} / B=M=3.79$ were greater than the $C_{L}$ values for weirs with $M=2.79$ and $M=1.78$ for the same weir height and $H_{T} / P$ ratios. The $C_{L}$ values for weirs with $M=2.79$ were also greater than the $C_{L}$ values for weirs with $M=1.78$. The consequences of headwater inflation may have been responsible for this. As the effective lengths of the labyrinth weirs, $L_{C}$, increased, the effect of headwater inflation reduced; a longer weir produces less headwater inflation $[2,5,15]$. As a result, by increasing the effective length of rectangular labyrinth weirs and increasing the $M$ values ( $L_{C} / B$ ratios), the effects of headwater inflation of rectangular labyrinth weirs can be mitigated.

According to Figure 20 and Table 5, the $C_{L}$ values of the M4 model (relative to M1) increased by 34.2 percent on average when the $M$ value increased from 1.78 to 2.79 (the effective length increased by 57 percent). While the $M$ value increased from 1.78 to 3.79 as the effective length increased by 113 percent, the $C_{L}$ values of the M7 model (compared to M1) increased by 57.2 percent on average.

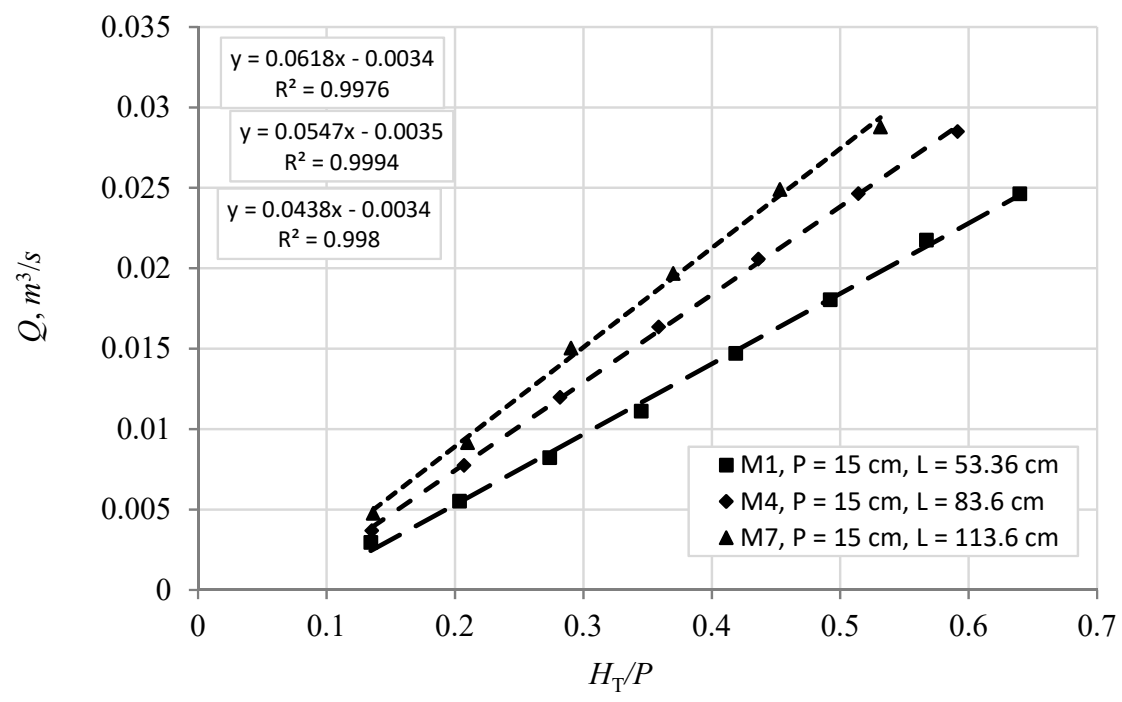

Figure 17. Total discharge, $\mathrm{Q}$, vs. $H_{T} / P$ for models M1, M4, and M7. 


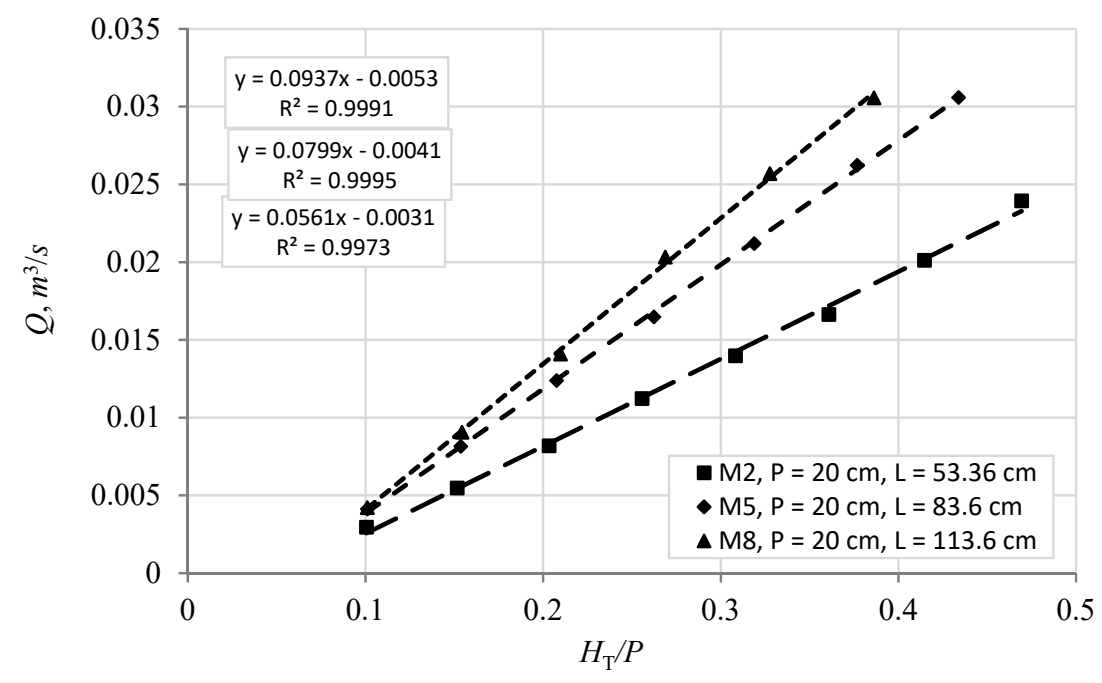

Figure 18. Total discharge, $\mathrm{Q}$, vs. $H_{T} / P$ for models M2, M5, and M8.

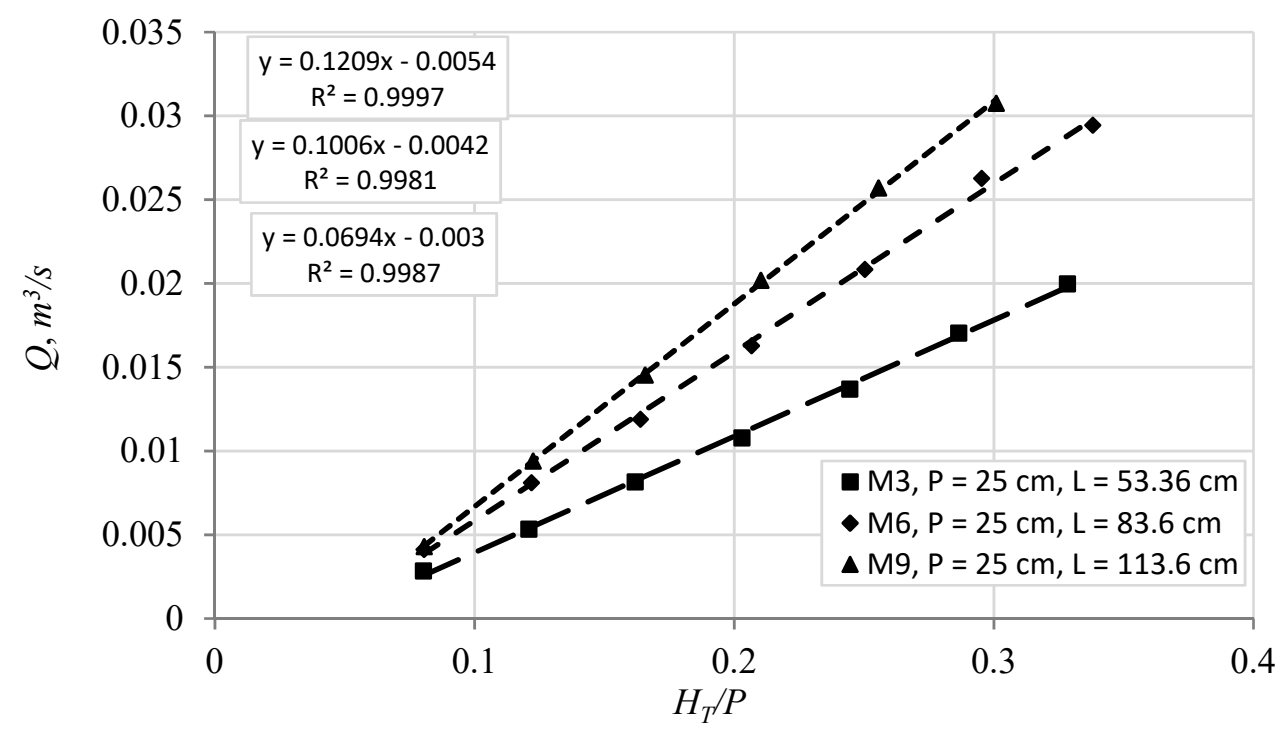

Figure 19. Total discharge, $\mathrm{Q}$, vs. $H_{T} / P$ for models M3, M6, and M9.

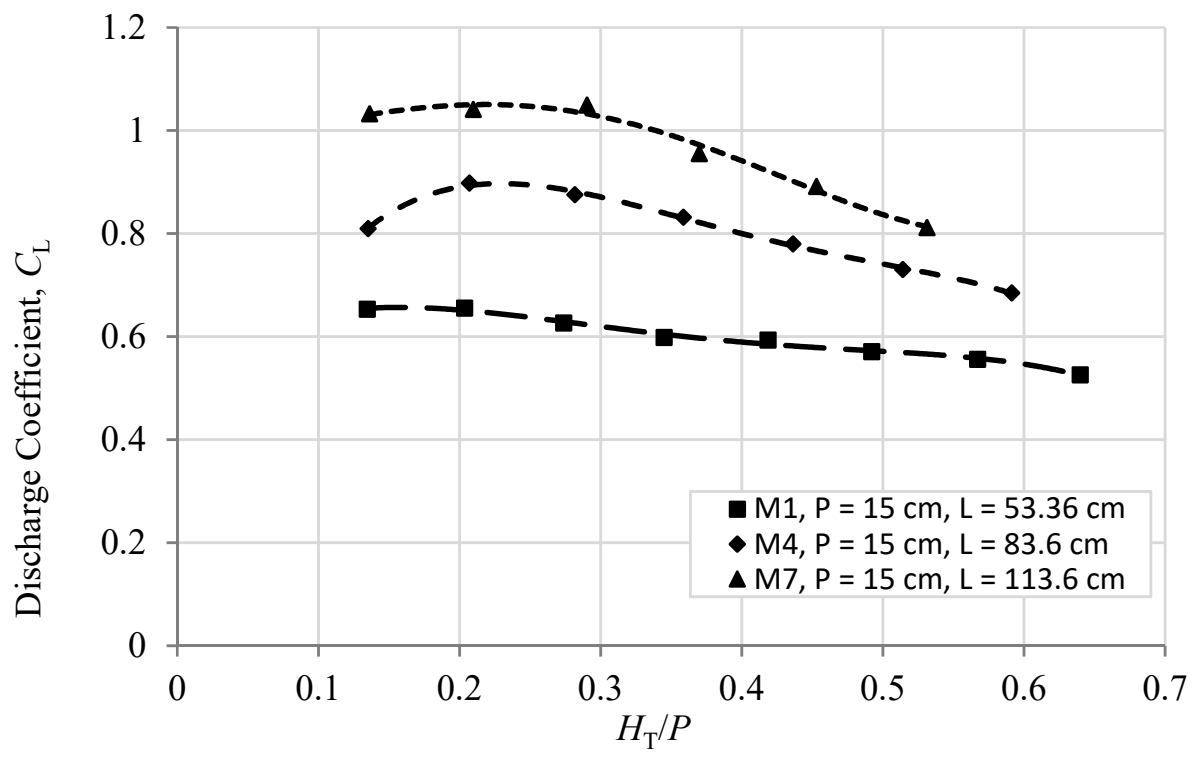

Figure 20. Discharge coefficient, $C_{L}$, vs. $H_{T} / P$ for models M1, M4, and M7. 


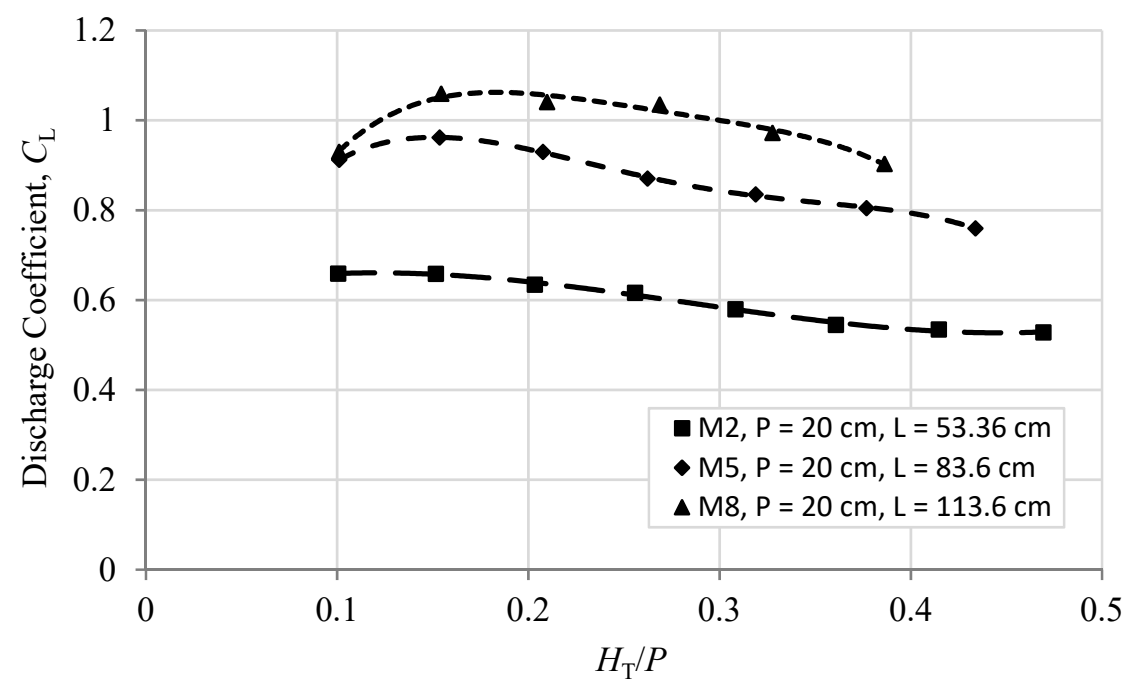

Figure 21. Discharge coefficient, $C_{L}$, vs. $H_{T} / P$ for models M2, M5, and M8.

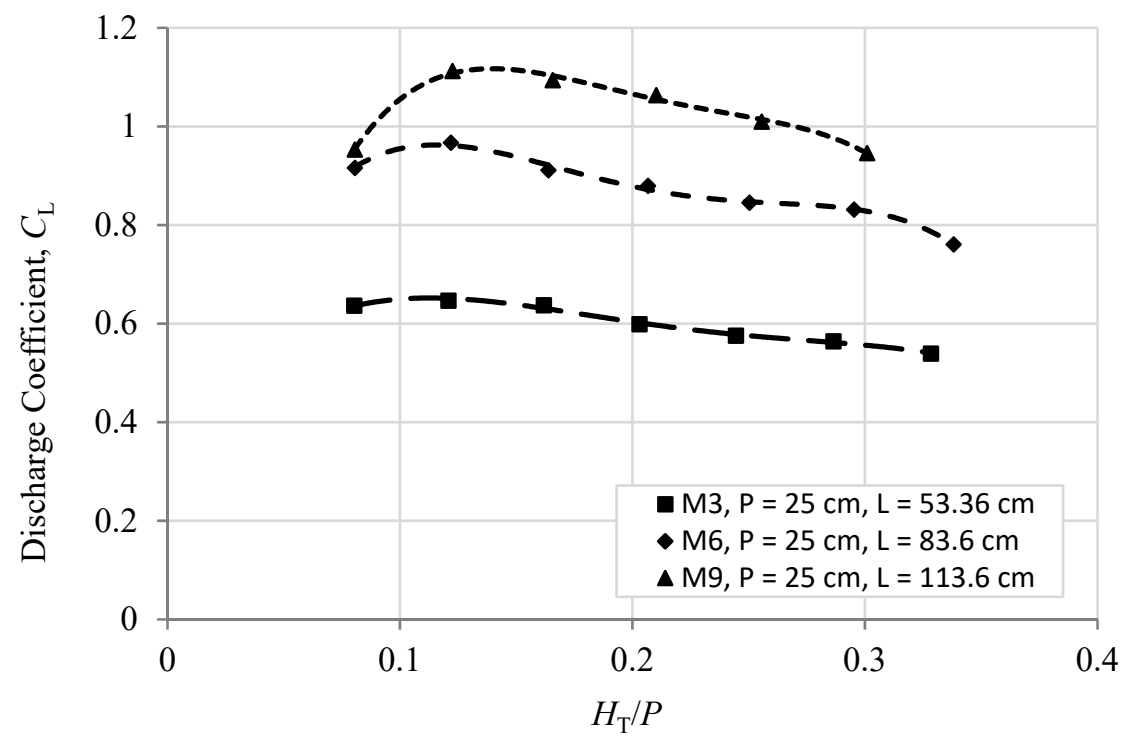

Figure 22. Discharge coefficient, $C_{L}$, vs. $H_{T} / P$ for models M3, M6, and M9.

Table 5. Changes in the total discharge and discharge coefficient due to the effective length.

\begin{tabular}{ccccccc}
\hline \multirow{2}{*}{ Parameters } & \multicolumn{7}{c}{ Percentage Changes } \\
\cline { 2 - 7 } & M4/M1 & M7/M1 & M5/M2 & M8/M2 & M6/M3 & M9/M3 \\
\hline Length ratios $L_{C} / L_{C}$ & 1.567 & 2.129 & 1.567 & 2.129 & 1.567 & 2.129 \\
Total Discharge $(Q)$ & $28.5-48.4$ & $47.8-85.2$ & $55-44$ & $62.1-66.4$ & $48-70.9$ & $76-89.7$ \\
Coefficient of & $(33.6)^{*}$ & $(57.5) *$ & $(46.9)^{*}$ & $(65.3) *$ & $(53.7) *$ & $(79.5)^{*}$ \\
Discharge $\left(C_{L}\right)$ & $26.8-40.5$ & $43-65.7$ & $38.1-46.7$ & $62.3-96.3$ & $44.2-48.8$ & $49.6-77.1$ \\
\hline
\end{tabular}

${ }^{*}$ Average values.

A similar pattern was seen for models M2, M5, and M8, as illustrated in Figure 21 and Table 5 . The $C_{L}$ values of the M5 model (relative to M2) increased by 44.2 percent on average as the effective length increased by 57 percent. The $C_{L}$ values of the M8 model (relative to M2) increased by 84.7 percent on average as the effective length increased by 113 percent.

For models M3, M6, and M9, the $C_{L}$ values of the M6 model (relative to M3) increased by 46.6 percent on average as the effective length increased by 57 percent. The $C_{L}$ values of 
the M9 model (relative to the M3) increased by 69.1 percent on average while the effective length increased by 113 percent, as shown in Figure 22 and Table 5.

\subsection{Regression Analysis}

Because varied values of $L_{C}, P$, and $h$ resulted in different $C_{B}$ values in Figures 15-22, there is a possibility that they are related. Accordingly, to find any probable correlation equations between discharge coefficients of round-cornered rectangular labyrinth weirs, $C_{B}$, and other parameters such as effective length $\left(L_{C}\right)$, weir height $(P)$, and water depth above the weir crest $(h)$, the discharge coefficient was chosen as the dependent variable in the linear analysis model, with the other variables serving as independent variables. As shown below, a linear relationship is assumed for the depiction of the relationship between the variables:

$$
C_{B}=\beta_{1}+\beta_{2}\left(\frac{L_{C}}{B}\right)+\beta_{3}\left(\frac{P}{B}\right)+\beta_{4}\left(\frac{h}{B}\right)
$$

where $\beta_{1}, \beta_{2}, \beta_{3}$, and $\beta_{4}$ are the model constants.

Sixty-two experimental results were employed in the multiple linear regression analysis. Forty-four (44) experimental results were utilized to determine the model, while the remaining data (18 results) were used to evaluate the model. The following equation emerged from the multiple linear regression analysis:

$$
C_{B}=0.553+0.333\left(\frac{L_{C}}{B}\right)+0.204\left(\frac{P}{B}\right)+1.094\left(\frac{h}{B}\right)
$$

The root mean square errors (RMSE), mean absolute errors (MAE), mean relative error percentage $(R E)$, and coefficient of determination $\left(R^{2}\right)$ for the multiple linear regression analysis were $0.8874,0.03943,4.75 \%$, and 0.9187 , respectively. Equation 4 was used to compare the observed discharge coefficients to the computed values in Figure 23. The measured values and the computed values from the proposed equation showed satisfactory agreement.

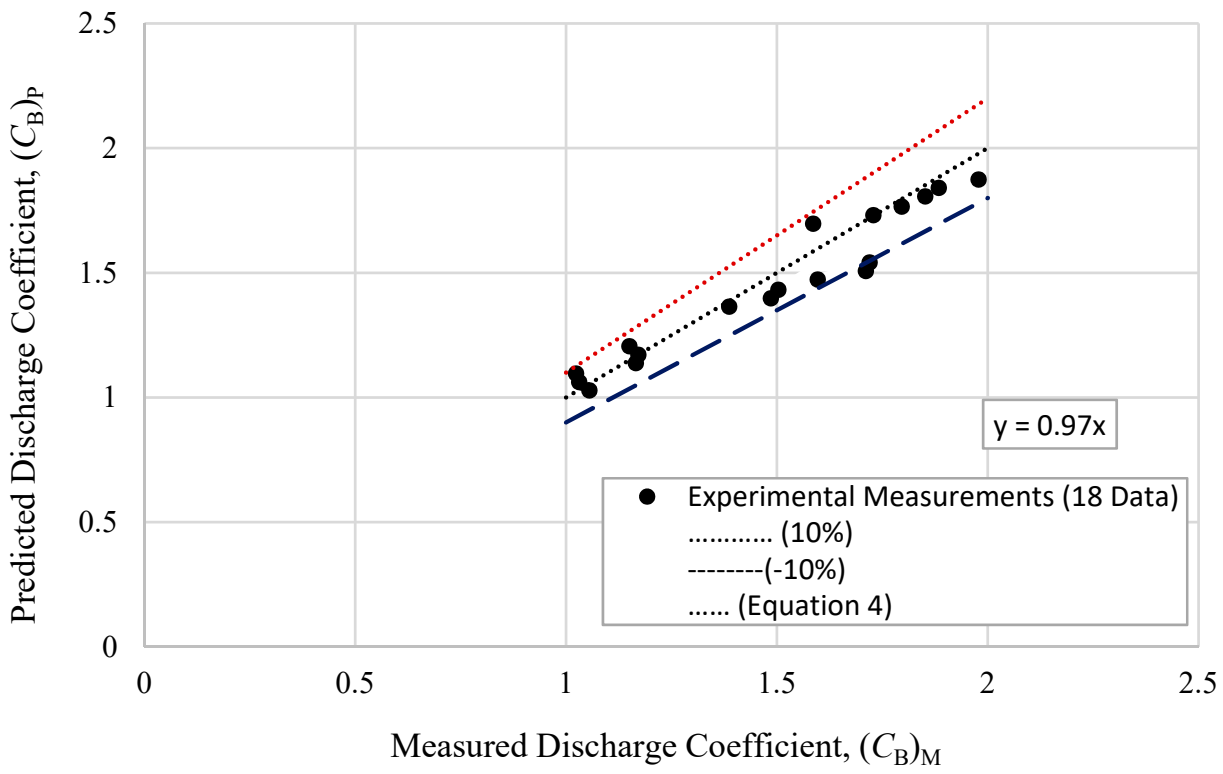

Figure 23. Measured vs. Calculated Discharge Coefficients $\left(C_{B}\right)$ for all models.

\section{Conclusions}

The hydraulic performance of the flow over round-cornered rectangular labyrinth weirs was investigated experimentally by varying the effective length and weir heights. In a prismatic flume, nine models were erected and tested. Next, the discharge coefficients for 
the nine models were calculated for various overflow discharges. The following conclusions can be drawn:

1. For round-cornered rectangular labyrinth weirs, the discharge coefficient, $C_{L}$, increases as the $H_{T} / P$ ratios increase until a certain value of $H_{T} / P$ is reached, after which $C_{L}$ values decrease steadily;

2. Round-cornered rectangular labyrinth weirs with greater $L_{C} / B$ ratios (higher $M$ values) showed higher hydraulic efficiency for the $H_{T} / P$ ranges utilized in this study, $0.1 \leq H_{T} / P \leq 0.65$. The discharge coefficient increased by 35.7 percent on average as the effective length increased by 57 percent. On average, the discharge coefficient increased by $70 \%$ while the effective length increased by 113 percent;

3. As the weir height $(P)$ increases, the hydraulic efficiency of round-cornered rectangular labyrinth weirs increases marginally. For the effective length of the weir to the channel width ratios $\left(L_{C} / B\right) \leq 1.78$, however, the influence of weir height diminishes;

4. One should increase the weir height or effective length to lessen the influence of headwater inflation and nappe interferences of flows across round-cornered rectangular labyrinth weirs;

5. Using multiple linear regression analysis, a satisfactory correlation equation was found between discharge coefficients of round-cornered rectangular labyrinth weirs, $C_{B}$, and the other parameters, namely the effective length $\left(L_{C}\right)$, weir height $(P)$, and water depth over the weir crest $(h)$.

Author Contributions: Conceptualization, O.S.Q.Y. and M.K.; methodology, W.Q., A.S.A., O.S.Q.Y. and K.Z.A.; data curation, O.S.Q.Y., W.Q. and A.S.A.; writing—original draft preparation, O.S.Q.Y.; writing—review and editing, M.K., K.Z.A., W.Q. and A.S.A.; supervision, O.S.Q.Y. and M.K.; All authors have read and agreed to the published version of the manuscript.

Funding: This research received no external funding.

Institutional Review Board Statement: Not Applicable.

Informed Consent Statement: Not Applicable.

Data Availability Statement: All data that support the findings of this study are available from the corresponding author upon reasonable request.

Acknowledgments: The tests were carried out in the Hydraulic Laboratory of the College of Engineering at the University of Sulaimani. Hiwa Karim Saeed and Goran Jalal Jamal provided help during the experimental work.

Conflicts of Interest: The authors declare no conflict of interest.

\section{References}

1. Bilhan, O.; Emiroglu, M.; Miller, C. Experimental Investigation of Discharge Capacity of Labyrinth Weirs with and without Nappe Breakers. World J. Mech. 2016, 6, 207-221. [CrossRef]

2. Crookston, B.M.; Tullis, B.P. Labyrinth weirs: Nappe interference and local submergence. J. Irrig. Drain Eng. 2012, 138, 757-765. [CrossRef]

3. Tullis, P.; Amanian, N.; Waldron, D. Design of labyrinth spillways. J. Hydraul. Eng. 1995, 121, 247-255. [CrossRef]

4. Taylor, G. The Performance of Labyrinth Weirs. Ph.D. Thesis, University of Nottingham, Nottingham, UK, 1968.

5. Azimi, A.H.; Hakim, S.S. Hydraulics of flow over rectangular labyrinth weirs. Irrig. Sci. 2019, 37, 183-193. [CrossRef]

6. Jansen, R.B. Advanced dam Engineering for Design, Construction, and Rehabilitation; Springer Science \& Business Media: Berlin/Heidelberg, Germany, 1988.

7. Safarrazavi Zadeh, M.; Esmaeili Varaki, M.; Biabani, R. Experimental study on flow over sinusoidal and semicircular labyrinth weirs. ISH J. Hydraul. Eng. 2019, 1-10. [CrossRef]

8. Crookston, B.M. Labyrinth Weirs. Ph.D. Dissertation, Utah State University, Logan, UT, USA, 2010.

9. Anderson, R.M.; Tullis, B.P. Comparison of piano key and rectangular labyrinth weir hydraulics. J. Hydraul. Eng. 2012, 138, 358-361. [CrossRef]

10. Kabiri-Samani, A.; Javaheri, A.; Borghei, S.M. Discharge coefficient of a rectangular labyrinth weir. ICE's Water Manag. 2013, 166, 443-451. [CrossRef]

11. Henderson, F.M. Open Channel Flow (No. 532 H4); Macmillan: New York, NY, USA, 1966. 
12. Rostami, H.; Heidarnejad, M.; Purmohammadi, M.H.; Kamanbedast, A.; Bordbr, A. An Experimental study into discharge coefficient of labyrinth weirs with rectangular-shaped plans. Fresen. Environ. Bull. 2016, 25, 5138-5144.

13. Emadi, A.R.; Rezaei, M. Experimental study of rectangular labyrinth weirs. J. Water Soil (Agric. Sci. Technol.) 2015, 29, 1438-1446.

14. Heidarour, M.; Mousavi, S.F.; Zarmehri, A.R. Investigation of rectangular and U-shaped labyrinth weirs. JWSS-Isfahan Univ. Technol. 2006, 10, 519-531.

15. Yousif, O.S.; Karakouzian, M. Effect of Corner Shape on Hydraulic Performance of One-Cycle Rectangular Labyrinth Weirs. Fluids 2020, 5, 117. [CrossRef] 